\title{
Diamonds from Zarnitsa and Dalnaya kimberlites (Yakutia): Their nature, growth history, and lithospheric mantle source
}

\author{
Bulanova, G.P. ${ }^{1,2}$, Griffin, W.L. ${ }^{2,3}$, Kaminsky, F.V. ${ }^{1}$, Davies, R. ${ }^{2}$, Ryan, C.G. ${ }^{3}$, Andrew, A. ${ }^{4}$,
} Spetsius, Z.V. ${ }^{5}$, and Zahkarchenko, O.D.'.

1. TsNIGRI, 129B Varshavsky sh., Moscow, Russia.

2. GEMOC National Key Centre, Macquarie University, NSW 2109, Australia

3. CSIRO Exploration and Mining, P.O. Box 136, North Ryde, NSW 2113, Australia

4. CSIRO Div. of Petroleum Exploration, P.O. Box 136, North Ryde, NSW 2113, Australia

5. Yakutniproalmaz, 39 Lenin St., Mirny, Yakutia

\section{Introduction}

This paper presents the results of study of diamonds from two pipes of the Daldyn-Alakit kimberlite field (Yakutia). Zarnitsa ("Flash of Summer Lightning"), the first kimberlite discovered in Siberia, is located $15 \mathrm{~km}$ E of Udachnaya. Dalnaya is a small pipe in the southern part of the Daldyn Field. No information on diamond parageneses from these late Devonian pipes has been published previously.

\section{Samples and methods}

About 45 diamonds $(-4+2$ and $-8+4 \mathrm{~mm})$ with mineral inclusions were selected from each pipe and their morphology and surface features were studied using a binocular microscope. Cathodoluminescence (CL) images and Fourier transform infrared (FTIR) measurements were done on the whole stones first. 22 stones from Dalnaya and 32 from Zarnitsa were then sawn by laser or polished mechanically parallel to the planes (110) or (100). Polished central plates have been prepared for some stones; others were polished down to expose inclusions. The internal morphology of the diamonds and the location of inclusions were studied by birefringence (BR) and CL. Inclusions were analysed in situ on the polished diamond surfaces for major element composition by electron microprobe and for trace elements by proton and laser microprobes. A few central inclusions (seeds) were studied by SEM imagery and analysis. Hydrogen and nitrogen concentrations and $\mathrm{N}$ aggregation state were investigated in the central diamond plates by FTIR. Carbon isotopic composition was determined by mass spectrometry for 20 stones, using fragments of diamond off-cuts.

\section{External morphology, colour and surface features.}

Diamonds from both pipes are most commonly octahedra and colourless, more rarely palebrown and pale-yellow; morphology is summarised in Table 1.

Table 1. Morphology of diamonds from Dalnaya and Zarnitsa

\begin{tabular}{|l|c|c|c|c|c|c|c|}
\hline Pipe & $\begin{array}{c}\text { no. } \\
\text { stones }\end{array}$ & Octahed. & $\begin{array}{l}\text { Octah/ } \\
\text { dodecah. }\end{array}$ & Dodec. & Cube & Macle & Coated \\
\hline Dalnaya & 45 & 23 & 7 & 7 & 5 & 2 & 1 \\
\hline Zarnitsa & 43 & 16 & 13 & 6 & 6 & 1 & 1 \\
\hline
\end{tabular}

The resorbed stones belong to category 3-4 (15-25\% resorption) of the classification of Robinson (in McCallum et al., 1994). Based on the small numbers of stones examined, those from Dalnaya appear to be generally less resorbed than those from Zarnitsa, and both localities show more resorption than stones from the Malo-Botuobinsky field (Bobrievich et al., 1959).

\section{Internal structure and history of growth}

Most diamonds studied from both pipes (ca $70 \%$ ) have simple octahedral zonation and blue $\mathrm{CL}$ colour, in agreement with data from other kimberlite pipes of Yakutia (Bulanova, 1995). These diamonds grew by a tangential mechanism of growth (layer by layer) and were slightly resorbed after growth. Only a few diamonds show a change of growth shape and CL colour during crystallisation, in the sequence (early to late): cubo-octahedron $Æ$ rounded octahedron $Æ$ octahedron (uncertain) $Æ$ octahedron. Cubo-octahedral and rounded zones have yellow or yellow- 
green CL colour. This change of growth form and CL colour is more typical for eclogitic diamonds from both pipes. The typomorphic feature of peridotitic diamonds is a fine octahedral zonation, as shown before for diamonds from other pipes in the Daldyn-Alakit and Malo-Botuobinsky fields (Bulanova, 1995). Some diamonds from both pipes show plastic deformation, internal resorption and dark (no CL) zones (type II diamond), reflecting the change of growth shape or other fluctuations in environmental conditions. These dark zones commonly appear in the following specific situations within diamond: (i) at the interface of changes in growth habit or layering, often in association with mineral inclusions, (ii) in discrete areas surrounding mineral inclusions, (iii) in broad patches with convolute lobed boundaries, extending from the edge of the diamond into the interior. In some cases the shape and position of these dark zones suggest second-generation diamond growth and infilling of cracks.

\section{FTIR study}

Nitrogen contents in Zarnitsa diamonds range from 36 to $2100 \mathrm{ppm}$, and aggregation states from 5-67 \%IaB (average 28\%); in Dalnaya diamonds the corresponding values are 75-1830 ppm and 5-74\% (aver. 35\%). Three Dalnaya diamonds were Type II. Hydrogen peaks were observed in $>1 / 3$ of the Zarnitsa stones and 1/2 of the Dalnaya stones. FTIR maps of central plates show large spatial variations in ppm $\mathrm{N}, \% \mathrm{IaB}$ and $\mathrm{H}$. In 7/9 of Dalnaya plates and 8/11 of Zarnitsa plates, $\mathrm{N}$ content and aggregation state decrease from core to rim, in some cases grading to Type II rims. The largest spatial variation in a plate from Dalnaya is $450-1200 \mathrm{ppm} \mathrm{N}$, and $28-37 \% \mathrm{IaB}$ aggregation; in Zarnitsa diamonds the largest range in a single plate is $35-2070 \mathrm{ppm}$ and $<10-67 \%$ $\mathrm{IaB}$. Correlation with $\mathrm{CL}$ images shows that $\mathrm{H}$ occurs not only in the cores of diamonds, but also at transitions between morphological type (resorption or overgrowth) and at boundaries between Type $\mathrm{IaAB}$ and Type II diamond. Platelet sizes for diamonds from both localities are large (1359 - 1372 $\mathrm{cm}^{-1}$ ). In general, FTIR results from both pipes are similar and imply that temperature/time/ deformation conditions during the history of the diamonds also were similar.I

\section{Mineral inclusions}

In both pipes the peridotitic inclusion paragenesis is more abundant than the eclogitic one (Zarnitsa, 23 of 30 stones; Dalnaya, 15 of 17 stones). The most common inclusions in peridotitic diamonds of both pipes are olivine (Fo 92-93) and chromite (62-67 wt $\% \mathrm{Cr}_{2} \mathrm{O}_{3}$ ). Subcalcic garnet is also common, but it is more abundant in Dalnaya diamonds. LAM-ICPMS analyses show that these garnets are strongly depleted in $\mathrm{HREE}(\mathrm{Sc} / \mathrm{Y}(\mathrm{CN})=14.7-35.8)$ and have sinuous REE patterns $(\mathrm{Nd} / \mathrm{Y}(\mathrm{CN})=2.7-10.7)$, like most such garnets worldwide. The Nickel Temperatures (Ryan et al., 1996) of 3 peridotitic garnets are $1210^{\circ} \mathrm{C}, 1340^{\circ} \mathrm{C}$ and $1370^{\circ} \mathrm{C}$; similar high $\mathrm{T}_{\mathrm{Ni}}$ are observed in high-Cr pyrope inclusions from Udachnaya diamonds (Griffin et al., 1993). Zinc Temperatures for 5 chromites from Zarnitsa average $950{ }^{\circ} \mathrm{C}$; these lie in the low end of the $\mathrm{T}_{\mathrm{Zn}}$ range for inclusions from Udachnaya. 3 inclusions of pentlandite were found in Zarnitsa diamonds and one in a diamond from Dalnaya; all contain Pt group elements. Clinopyroxene and enstatite were not found in the peridotitic diamonds. In the eclogitic diamonds ( 5 for Zarnitsa and 2 for Dalnaya) sulphides, omphacites and pyrope-almandine garnets were found in equal proportions . Sulphides occur as individual inclusions, sometimes in association with garnet and omphacite, and sometimes in intimate intergrowths with these minerals. The chemistry of major elements of garnet and omphacite is similar to inclusion chemistry from other localities in Siberia (Bulanova et al., 1993; Sobolev, 1976). Eclogitic garnets have high HREE and depleted LREE, while eclogitic cpx have essentially flat REE patterns.

\section{Central inclusions (seeds)}

Black micro-inclusions were identified in the genetic centre of many of the diamonds. From SEM study they were identified as sulphides, Fe-phase + graphite and cohenite (Fe-carbide), as found in seeds of other Yakutian diamonds (Bulanova, 1995; Bulanova et al., 1998). This indicates that diamond nucleated on these minerals, which may have catalysed diamond growth. 


\section{Isotopic composition of carbon}

The carbon-isotope composition was measured in 28 fragments from 20 stones. The values of $\partial^{13} \mathrm{C}$ for all but one stone range from +0.75 to -8 , with an average of $-4.1 \%$ and a median of $-4.0 \%$. One eclogitic stone from Zarnitsa, with an inclusion of low-Ni sulfide, gave $\partial^{13} \mathrm{C}=-$ $12.49 \%$. In most cases analyses of fragments from different parts of individual stones are reproducible within $\pm 0.1 \%$. However, a coated stone from Zarnitsa gave values of $\partial^{13} \mathrm{C}=-8.0$ (interior) and $-6.8 \%$ (coat), and one stone from Dalnaya gave values of $-0.43 \%$ (interior) and $+0.75 \%$ (rim).

\section{Conclusions}

Diamondiferous rocks in the mantle beneath the Dalnaya pipe are mainly harzburgitic/dunitic, as in most commercial-grade Siberian pipes. Beneath Zarnitsa the proportion of diamondiferous eclogite may be higher, and similar to Mir, where the eclogitic assemblage amounts to $30 \%$ (Bulanova, 1995). The degree of resorption of the stones studied here is much higher than in nearby commercial-grade pipes; this difference may be related to the much greater incidence of high$\mathrm{T}$ metasomatism recorded in the concentrate garnets and xenoliths from Zarnitsa and Dalnaya.

\section{References}

Bobrievich, A.P., Bondarenko, M.N., Gnevushev, M.A., Krasov, A.M., Smirnov, G.I., and Yurkevich, R.K., 1959, The diamond deposits of Yakutia. Gosgeoltekhizdat, Moscow, 527 pp. (in Russian).

Bulanova, G.P., Barashkov, Yu.P., Talnikova, S.B., and Smelova, G.B., 1993, Natural diamond - genetic aspects. Nauka, Novosibirsk, 176 pp. (in Russian)

Bulanova, G.P., 1995, . The formation of diamond, J. Geochem. Explor., 53, 1-23.

Bulanova, G.P., Griffin, W.L. and Ryan, C.G., 1998, Nucleation environment of Yakutian diamonds, Mineral. Mag. (in press).

Griffin W.L., Sobolev, N.V., Ryan C.G., Pokhilenko, N.P, Win, T.T. and Yefimova, Y., 1993, Trace elements in garnets and chromites: diamond formation in the Siberian lithosphere, Lithos, 29, 235-256.

McCallum, M.E., Huntley, P.M., Falk, R.W., and Otter, M.L., 1994, Morphological, resorption and etch feature trends of diamonds from kimberlitic populations within the Colorado-Wyoming State Line District, USA, In: H.O.A. Meyer and O.H. Leonardos (Editors), CPRM Spec. Publ. $1 / \mathrm{B}, 15-50$.

Ryan, C.G., Griffin, W.L. and Pearson, N.J., 1996, Garnet Geotherms: a technique for derivation of P-T data from Cr-pyrope garnets, Jour Geophys. Res., 101, 5611-5625..

Sobolev, N.V. 1974. Deep seated xenoliths in kimberlites and the problem of the composition of the upper mantle. Nauka, Novosibirsk, 264 pp. (in Russian). 